\title{
Age-related limitations of interleukin- 6 in predicting early mortality in acute ST-elevation myocardial infarction
}

\author{
Dominika Kanikowska ${ }^{1 * \dagger}$, Małgorzata Pyda ${ }^{2 \dagger}$, Katarzyna Korybalska' ${ }^{1}$ Stefan Grajek², Maciej Lesiak², \\ Andrzej Bręborowicz ${ }^{1}$ and Janusz Witowski ${ }^{1}$
}

\begin{abstract}
Interleukin-6 (IL-6) is an inflammatory cytokine whose levels increase significantly during myocardial infarction (MI). It has been hypothesised that the concentrations of IL-6 at admission may be useful in prognosticating long-term outcomes. It is unclear, however, whether IL-6 could improve the prognosis of early mortality in MI. We have compared serum IL-6 levels and analysed the disease course in 158 patients with ST-elevation MI (STEMI) who either survived $(n=148)$ or died $(n=10)$ within 30 days following the admission. Patients were treated in a single university centre with primary percutaneous coronary intervention (PCl).

The non-survivors (6.3\%) displayed most of typical risk factors for poor outcome. In addition they had significantly higher concentrations of IL-6 at hospital admission (median values $8.5 \mathrm{vs} .2 .0 \mathrm{pg} / \mathrm{ml} ; \mathrm{p}=0.038$ ). However, they were also significantly older than the survivors (median values 72 vs. 57 years; $p=0.0001$ ). IL-6 levels are known to increase with age and we could confirm a significant correlation between patients' calendar age and circulating IL-6 ( $p=0.009)$. Regression analysis revealed that IL-6 concentrations were significantly affected by patients' age but they did not independently relate to patients' outcome.

Such results indicate that circulating IL-6 at admission may be of limited value in predicting early mortality in STEMI. It is important to recognize that, because of the small group of patients who died $(N=10)$, the results must be interpreted with caution. Therefore, we stress that these results should be viewed as preliminary and further validated in a larger set of patients.
\end{abstract}

Keywords: Aging, Interleukin-6, Mortality, Myocardial infarction

\section{Introduction}

IL-6 is a key mediator of inflammation [1,2] and as such has been implicated in the pathogenesis of atherosclerosis and coronary artery disease (CAD) [3]. Biological effects of IL-6 are mediated either by classic IL- 6 receptor (IL-6R) or by trans-signalling via soluble IL-6R (sIL-6R) [4]. Positive associations between circulating IL-6 concentrations and the risk of CAD have been consistently observed [5]. Mendelian randomization studies indicate there might exist causal association between signalling through IL-6R and CAD [6].

\footnotetext{
* Correspondence: dkanikowska@ump.edu.pl

${ }^{\dagger}$ Equal contributors

'Department of Pathophysiology, Poznan University of Medical Sciences, Rokietnicka 8, 60-806 Poznań, Poland

Full list of author information is available at the end of the article
}

Moreover, results of several studies suggest that high IL-6 levels during acute coronary syndromes (ACS) may be associated with worse long-term prognosis [7-13]. Less clear is the link between IL- 6 and early mortality in ACS. On the one hand, high IL-6 was proposed to predict 30-day mortality in patients with cardiogenic shock after myocardial infarction $[14,15]$. On the other hand, the association of high baseline IL- 6 concentrations with increased mortality within 16 weeks after ACS became insignificant when adjusted for known covariates [9].

Chronologic age is a strong independent risk factor for increased morbidity and mortality from ACS $[16,17]$. The role of age as a covariate may be of particular importance in interpreting IL- 6 data. It is because ageing is 
associated with a rise in circulating IL-6, which may be related both to an increased prevalence of cardiovascular risk factors and to ageing per se $[18,19]$. The relative contribution of these process is difficult to estimate and differs probably between the populations studied.

We thought we could add to this debate by examining if serum levels of IL- 6 recorded at admission predict 30-day mortality in patients with myocardial infarction. Experimentally, such a study would require groups of patients who had been controlled for age and other risk factors, including duration of CAD. However, in practice, this would be very difficult to achieve. Accordingly, the effect of such factors has been taken into account statistically.

\section{Material and methods}

Samples from 158 patients with acute ST-elevation myocardial infarction (STEMI) were analysed. Blood samples were taken in the acute phase of STEMI on admission to the hospital and before primary PCI. The diagnosis was based on typical clinical, biochemical, and electrocardiographic criteria. All patients underwent primary percutaneous coronary intervention (PCI) within 12 hours after the onset of chest pain. The procedure was performed according to standard institutional practices with stenting whenever possible. After PCI the patients were maintained on standard dual anti-platelet therapy (aspirin, clopidogrel), $\beta$-blockers, and angiotensin-converting enzyme inhibitors. Statins (atorvastatin or simvastatin) were introduced 48 hours after PCI. Patients with pre-existing autoimmune or inflammatory disease, malignancy, immunosuppression, and prior therapy with statins were not included in the analysis, as these conditions may independently affect IL-6 levels.

IL-6 and sIL-6R were measured with enzyme-linked immunosorbent assay using DuoSet Development kits (R\&D Systems, USA). The assays were performed as per manufacturer's instructions. Sensitivity of the assays, as calculated by adding two standard deviations to the mean read-out for blank samples $(n=16)$, was $2 \mathrm{pg} / \mathrm{ml}$ and $9 \mathrm{pg} / \mathrm{ml}$ for IL-6 and sIL-6R, respectively. To enable logarithmic transformation, values below the limit of detection were assigned a value of 0.1 rather than zero.

Statistical analyses were performed using SPSS v.20 software (IBM, USA). The comparisons were made between patients who either survived or died within 30 days after STEMI. The normally distributed data were analysed using t-tests and Pearson's correlation; the data that were not distributed normally were compared using Mann-Whitney's U-test and Spearman's correlation. For regression analysis, the abnormally distributed data were log transformed. In this analysis, possible confounders (age and length of time before the cardiac event that CAD had been experienced) were incorporated in order to focus upon the issue of whether or not the variables of interest were associated with patient survival. Categorized data were analysed with the Fisher's test. The level of significance was set at $\mathrm{P}<0.05$.

\section{Ethical approval}

Ethics Committee of the Poznan University of Medical Sciences.

\section{Results}

Of 158 STEMI patients analysed, 10 (6.3\%) died within 30 days. Eight deaths occurred during initial hospitalization and were related to either cardiogenic shock (7 patients) or ventricular fibrillation ( 1 patient). The characteristics of patients from the two groups are listed in Table 1. Mean time from the onset of pain to PCI (total ischemic time) in survivors was $4.2+/-2.6$ hours and in non-survivors was $7.1+/-2.0$ hours $(\mathrm{p}<0.001)$.

The differences observed were not unexpected and included rather predictable parameters, such as age, time to treatment, long-term multiple-vessel CAD, high Killip-Kimball class, higher CPK, in-hospital events, and complicated PCI [20]. Interestingly, the levels of IL-6 at admission were significantly higher in patients who subsequently died compared with those who survived. Concentrations of sIL-6R did not differ between the groups.

The above data suggested that high IL-6 concentrations might be predicting early mortality in STEMI. However, patients who died were also significantly older $(57.8 \pm 0.9$ vs. $72.6 \pm 2.3$ years $)$. Serum IL-6 levels are known to increase with age [18] and, indeed, such a correlation was evident also in our patient population (Spearman $\mathrm{r}=0.2047, \mathrm{p}=0.009$; Figure 1). Therefore, the difference in IL-6 observed had to be corrected for age in order to determine whether it could be specifically related to patients' outcome. To this end, a regression analysis was performed using age and outcome (treated as a dichotomous variable with " 0 " and " 1 " for survivors and non-survivors, respectively) as the predictors. Values of log [IL-6] were predicted significantly in this model $\left(\mathrm{F}_{2,155}=4.72, \mathrm{p}=0.01\right)$. The standardized beta-coefficient for age was positive and significant $(p=0.042)$, whereas that for outcome was positive (higher in those who died) but not significantly so $(\mathrm{p}=0.139)$ (Table 2$)$. In addition, even though CAD was $2.6 \mathrm{x}$ more prevalent in patients who died than in those who survived ( $\mathrm{P}=0.014$, $\mathrm{t}$-test), incorporating prior duration of CAD into the regression equation showed that it was not a significant predictor $(\mathrm{P}=0.54)$ and the results were, essentially, unchanged. 
Table 1 Patient characteristics

\begin{tabular}{|c|c|c|c|}
\hline & Survivors $(n=148)$ & Non-survivors $(n=10)$ & $P$ \\
\hline \multicolumn{4}{|l|}{ Demographic parameters } \\
\hline Age, yrs & $57(50-64)$ & $72(68-80)$ & 0.0001 \\
\hline Gender (men,\%) & 70 & 72 & 1.00 \\
\hline $\mathrm{BMI}(\mathrm{kg} / \mathrm{m} 2)$ & $26.0(24.1-28.0)$ & $25.0(21.0-26.8)$ & 0.27 \\
\hline \multicolumn{4}{|l|}{ Medical history } \\
\hline Hypertension,\% & 45 & 45 & 1.00 \\
\hline Diabetes, $\%$ & 13 & 20 & 0.63 \\
\hline Smoking,\% & 65 & 30 & 0.042 \\
\hline Previous angina, $\%$ & 20 & 70 & 0.0006 \\
\hline Prior Ml,\% & 9 & 0 & 0.60 \\
\hline \multicolumn{4}{|l|}{ Current disease } \\
\hline Time to treatment, hrs & $3.5(2.5-5.0)$ & $7.0(4.0-9.0)$ & 0.003 \\
\hline Max. QRS duration, ms & $90(80-100)$ & $100(93-120)$ & 0.60 \\
\hline$E F, \%$ & $61(50-72)$ & $56(45-63)$ & 0.003 \\
\hline Killip-Kimball class >1,\% & 3 & 64 & 0.0001 \\
\hline \multicolumn{4}{|l|}{ Angiographic parameters } \\
\hline$>1$ vessel affected, $\%$ & 47 & 90 & 0.016 \\
\hline TIMI (0-2) before $\mathrm{PCI}, \%$ & 93 & 100 & 1.00 \\
\hline TIMI (0-2) after PCI,\% & 32 & 60 & 0.091 \\
\hline CTFG & $24(30-32)$ & $25(31-100)$ & 0.019 \\
\hline MBG $(0-1), \%$ & 32 & 60 & 0.091 \\
\hline Abciximab, $\%$ & 26 & 70 & 0.008 \\
\hline PCl complications,\% & 5 & 40 & 0.009 \\
\hline \multicolumn{4}{|l|}{ Laboratory findings } \\
\hline CPK, U/I & 1649 (740-2699) & 3473 (2544-4885) & 0.011 \\
\hline CK-MB, U/I & $159(62-273)$ & $371(271-520)$ & 0.014 \\
\hline$c T n l(\mu g / l)$ & $16(3-45)$ & $7(1-30)$ & 0.62 \\
\hline Total cholesterol, mmol/l & $5.9(5.2-7.2)$ & $6.2(5.6-6.8)$ & 0.78 \\
\hline LDL cholesterol, mmol/l & $3.9(3.2-4.8)$ & $3.9(3.4-4.4)$ & 0.93 \\
\hline HDL cholesterol, mmol/l & $1.4(1.2-1.7)$ & $1.3(1.1-1.7)$ & 0.64 \\
\hline Triglycerides, mmol/l & $1.5(1.1-2.2)$ & $1.6(0.9-2.6)$ & 0.93 \\
\hline Glucose, mmol/l & $6.4(5.6-7.7)$ & $9.3(7.3-14.1)$ & 0.002 \\
\hline CRP (mg/l) & $2.2(0.7-6.3)$ & $2.0(1.3-6.0)$ & 0.74 \\
\hline Creatinine, $\mu \mathrm{mol} / \mathrm{l}$ & $84(73-96)$ & $94(74-127)$ & 0.26 \\
\hline IL-6, pg/ml & $2.0(0.1-9.0)$ & $8.5(2.5-20.0)$ & 0.032 \\
\hline $\mathrm{slL}-6 \mathrm{R}, \mathrm{ng} / \mathrm{ml}$ & $53.0(41.6-66.2)$ & $51.1(32.9-65.1)$ & 0.58 \\
\hline
\end{tabular}

Abbreviations: $B M I$ body mass index, CK-MB creatine kinase-myocardial band isoform, CPK creatine phosphokinase, CRP C-reactive protein, CTFC corrected TIMI frame count, $E F$ ejection fraction, $H D L$ high density lipoprotein, IL-6 interleukin-6, IL-6sR interleukin-6 soluble receptor, $L D L$ low density lipoprotein, $M B G$ myocardial blush grade, TIMI thrombolysis in myocardial infarction scale.

Comparisons were made between patients who survived and those who died within 30 days after STEMI. Values are the medians (and interquartile ranges) or percentages.

To confirm the results obtained, we applied a different method of correcting for age. For this analysis only those survivors were selected $(n=17)$, who were of the same age as those who died $(59,67,68,72,77,80$ and
83 years). This approach made the two groups more similar in age and number (Table 3). Levels of IL-6, log [IL-6] and sIL-6RS in these groups were not at all significantly different. 


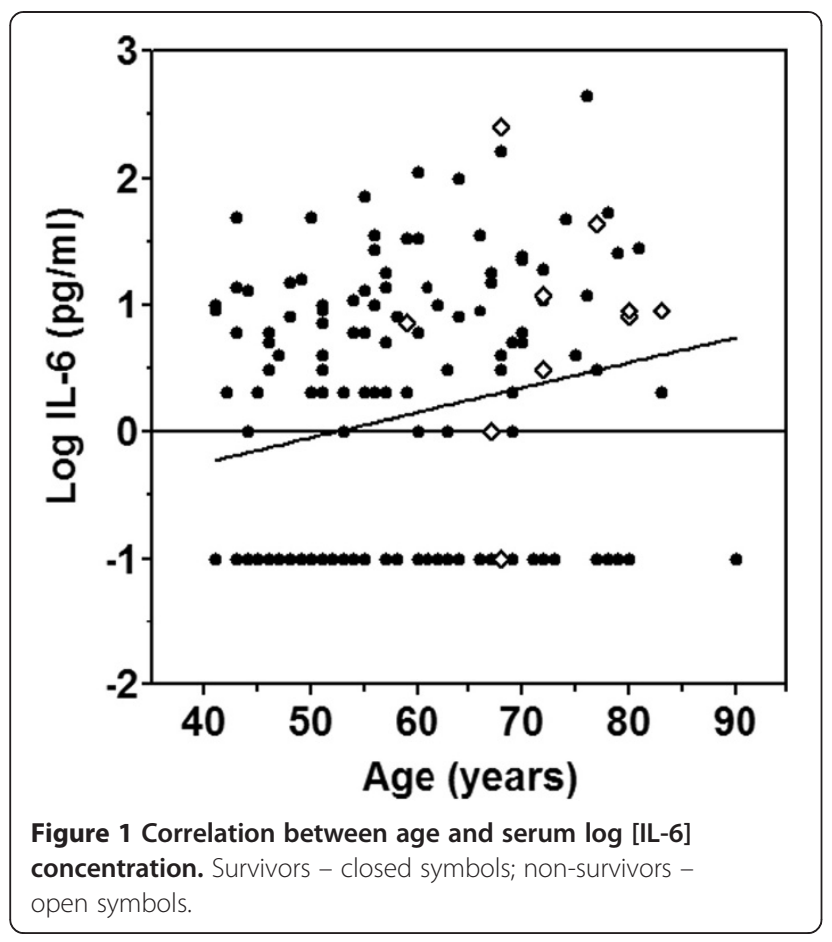

Taken together, these results imply that IL-6 concentration had been significantly affected by patients' age but not independently by patients' outcome.

\section{Discussion}

Increased levels of IL- 6 found in the elderly reflect predominantly an increased prevalence of cardiovascular risk factors or subclinical cardiovascular abnormalities, and the presence of other age-related diseases. Nevertheless, the rise in IL- 6 with age is seen even after adjusting for these variables, which may suggest there exists an age-associated dysregulation of IL- 6 production $[18,19,21,22]$. Therefore, the interpretation of increased IL-6 concentrations in the elderly in the context of CAD may be difficult. On the one hand, age-related increase in pro-inflammatory cytokines may pave the way for the disease; on the other hand it may blur a disease-specific increase in cytokine release.

Older individuals with low risk profile might have been under-represented in some studies. When, however, the elderly population is more specifically targeted, the
Table 3 Comparison of survivors and non-survivors of similar age

\begin{tabular}{llll}
\hline & Survivors $(\mathbf{n}=\mathbf{1 7})$ & Non-survivors $(\mathbf{n}=\mathbf{1 0})$ & $\mathbf{P}$ \\
\hline Age, yrs & $69.1 \pm 1.8$ & $72.6 \pm 2.3$ & 0.25 \\
$\mathrm{Log}[\mathrm{LL}-6], \mathrm{pg} / \mathrm{ml}$ & $0.46 \pm 0.28$ & $0.84 \pm 0.28$ & 0.31 \\
SIL-6R, ng/ml & $51.6 \pm 4.5$ & $50.5 \pm 4.9$ & 0.86 \\
\hline $\begin{array}{l}\text { Only survivors of the same age as non survivors were analysed. Values are } \\
\text { presented as means } \pm \text { SE. }\end{array}$
\end{tabular}

IL-6 assessment appears to improve long-term prediction of future CAD events [23]. It needs to be determined whether the same holds true for early mortality after STEMI. Although our observations indicate it might not always be the case, more well-powered studies would be required.

Including the prior duration of CAD in the regression calculation showed that it was not a significant predictor of patient outcome. Furthermore, we chose to analyse only patients with no history of previous therapy with statins as they are known to damp inflammation and decrease IL-6 release [24,25]. It would be interesting to determine whether earlier exposure to statins impacts on the value of IL-6 (or the lack of it) in predicting early mortality in patients with STEMI treated with primary PCI.

It is accepted that, because of the small group of patients who died $(\mathrm{N}=10)$, care must be taken with interpreting the results, whether they are statistically significant (when a larger sample is required to confirm this difference) or non-significant (when a Type II error might be present). Therefore, any interpretation of the present results must be considered speculative, and need to be confirmed in a larger set of patients.

For the moment, the results of our small single-centre study suggest that high IL-6 levels observed at baseline in non-survivors are related more to their advanced aged rather than point independently to an increased risk of early death. It is accepted that percutaneous coronary intervention (PCI) and coronary artery bypass grafting (CABG) are both good options for patients with advanced CAD [26]. Nevertheless, the challenge of finding optimal markers of long-term prognosis in such patients remains. The present study indicates that levels of IL- 6 do not seem to be sufficiently disciminatory in this regard.

Table 2 Predictors of serum log [IL-6] in STEMI

\begin{tabular}{|c|c|c|c|c|c|c|}
\hline \multicolumn{2}{|c|}{ Model } & \multicolumn{2}{|c|}{ Unstandardized coefficients } & \multirow{2}{*}{$\begin{array}{l}\text { Standardized coefficients } \\
\text { Beta }\end{array}$} & \multirow[t]{2}{*}{$\mathbf{t}$} & \multirow[t]{2}{*}{ Significance } \\
\hline & & B & Std. Error & & & \\
\hline \multirow[t]{3}{*}{1} & Constant & -.841 & .457 & & -1.839 & .068 \\
\hline & Age & .016 & .008 & .169 & 2.049 & .042 \\
\hline & Outcome & .521 & .350 & .123 & 1.487 & .139 \\
\hline
\end{tabular}




\section{Abbreviations}

ACS: Acute coronary syndromes; BMI: Body mass index; CAD: Coronary artery disease; CK-MB: Creatine kinase-myocardial band isoform; CPK: Creatine phosphokinase; CRP: C-reactive protein; CTFC: Corrected TIMI frame count; EF: Ejection fraction; HDL: High density lipoprotein; IL-6: Interleukin-6; IL-6R: IL-6 receptor; LDL: Low density lipoprotein; MBG: Myocardial blush grade; MI: Myocardial infarction; PCl: Percutaneous coronary intervention; sIL-6R: Soluble IL-6 receptor; STEMI: ST-elevation myocardial infarction; TIMI: Thrombolysis in myocardial infarction scale.

\section{Competing interests}

The authors declare that they have no competing interests.

\section{Authors' contributions}

Study concept and design: JW, MP, AB; data acquisition: MP, ML, SG; data analysis and interpretation: DK, KK, MP, JW; drafting the manuscript: DK, JW: critical revision of the manuscript for important intellectual content: JW, $A B$, SG; statistical analysis: DK, JW; administrative and technical support: SG, ML, AB; study supervision: JW. All authors read and approved the final manuscript.

\section{Acknowledgement}

The authors wish to thank Professor J. Waterhouse (Liverpool John Moores University, UK) for his advice regarding the analysis of the results.

\section{Author details}

'Department of Pathophysiology, Poznan University of Medical Sciences, Rokietnicka 8, 60-806 Poznań, Poland. ${ }^{2} 1$ st Department of Cardiology, Poznan University of Medical Sciences, Poznan, Poland.

Received: 24 September 2014 Accepted: 24 November 2014 Published online: 04 December 2014

\section{References}

1. Mihara M, Hashizume M, Yoshida H, Suzuki M, Shiina M: IL-6/IL-6 receptor system and its role in physiological and pathological conditions. Clin SC (Lond) 2012, 122:143-159.

2. Rincon M: Interleukin-6: from an inflammatory marker to a target for inflammatory diseases. Trends Immunol 2012, 33:571-577.

3. Hartman J, Frishman WH: Inflammation and atherosclerosis: a review of the role of interleukin- 6 in the development of atherosclerosis and the potential for targeted drug therapy. Cardiol Rev 2014, 22(3):147-51.

4. Scheller J, Chalaris A, Schmidt-Arras D, Rose-John S: The pro- and anti-inflammatory properties of the cytokine interleukin-6. Biochim Biophys Acta 2011, 1813:878-888.

5. Danesh J, Kaptoge S, Mann AG, Sarwar N, Wood A, Angleman SB, Wensley F, Higgins JP, Lennon L, Eiriksdottir G, Rumley A, Whincup PH, Lowe GD, Gudnason V: Long-term interleukin-6 levels and subsequent risk of coronary heart disease: two new prospective studies and a systematic review. PLOS Med 2008, 5:e78.

6. Hingorani AD, Casas JP: The interleukin- 6 receptor as a target for prevention of coronary heart disease: a mendelian randomisation analysis. Lancet 2012, 379:1214-1224.

7. Garcia-Salas JM, Tello-Montoliu A, Manzano-Fernandez S, Casas-Pina T, Lopez-Cuenca A, Perez-Berbel P, Puche-Morenilla C, Martínez-Hernández P, Valdés M, Marín F: Interleukin-6 as a predictor of cardiovascular events in troponin-negative non-ST elevation acute coronary syndrome patients. Int J Clin Pract 2014, 68:294-303.

8. Su D, Li Z, Li X, Chen Y, Zhang Y, Ding D, Deng X, Xia M, Qiu J, Ling W: Association between serum interleukin- 6 concentration and mortality in patients with coronary artery disease. Mediators Inflamm 2013, 2013:726178.

9. Zamani P, Schwartz GG, Olsson AG, Rifai N, Bao W, Libby P, Ganz P, Kinlay S, Myocardial Ischemia Reduction with Aggressive Cholesterol Lowering (MIRACL) Study Investigators: Inflammatory biomarkers, death, and recurrent nonfatal coronary events after an acute coronary syndrome in the MIRACL study. J Am Heart Assoc 2013, 2:e003103.

10. Hartford M, Wiklund O, Mattsson HL, Persson A, Karlsson T, Herlitz J, Caidahl K: C-reactive protein, interleukin-6, secretory phospholipase A2 group IIA and intercellular adhesion molecule- 1 in the prediction of late outcome events after acute coronary syndromes. J Intern Med 2007, 262:526-536.
11. Kavsak PA, Ko DT, Newman AM, Palomaki GE, Lustig V, Macrae AR, Jaffe AS: "Upstream markers" provide for early identification of patients at high risk for myocardial necrosis and adverse outcomes. Clin Chim Acta 2008, 387:133-138.

12. Bennermo M, Nordin M, Lundman P, Boqvist S, Held C, Samnegard A, Ericsson CG, Silveira A, Hamsten A, Nastase MM, Tornvall P: Genetic and environmental influences on the plasma interleukin- 6 concentration in patients with a recent myocardial infarction: a case-control study. J Interferon Cytokine Res 2011, 31:259-264.

13. Kazmierczak E, Grajek S, Kowal J, Chmara E, Grygier M, Pyda M, Bogdanski $P$, Cieslewicz A, Jablecka A: Prognostic usefulness of IL-6 and VEGF for the occurrence of changes in coronary arteries of patients with stable angina and implanted stents. Eur Rev Med Pharmacol Sci 2014, 18(15):2169-2175.

14. Geppert A, Dorninger A, Delle-Karth G, Zorn G, Heinz G, Huber K: Plasma concentrations of interleukin-6, organ failure, vasopressor support, and successful coronary revascularization in predicting 30-day mortality of patients with cardiogenic shock complicating acute myocardial infarction. Crit Care Med 2006, 34:2035-2042.

15. Prondzinsky R, Unverzagt S, Lemm H, Wegener NA, Schlitt A, Heinroth KM, Dietz S, Buerke U, Kellner P, Loppnow H, Fiedler MG, Thiery J, Werdan K, Buerke M: Interleukin- $6,-7,-8$ and -10 predict outcome in acute myocardial infarction complicated by cardiogenic shock. Clin Res Cardiol 2012, 101:375-384

16. Shanmugasundaram M, Alpert JS: Acute coronary syndrome in the elderly. Clin Cardiol 2009, 32:608-613.

17. De Luca G, Suryapranata H, van 't-Hof AW, de Boer MJ, Hoorntje JC, Dambrink JH: Prognostic assessment of patients with acute myocardial infarction treated with primary angioplasty: implications for early discharge. Circulation 2004, 109:2737-2743.

18. Ferrucci L, Corsi A, Lauretani F, Bandinelli S, Bartali B, Taub DD, Guralnik JM, Longo DL: The origins of age-related proinflammatory state. Blood 2005, 105:2294-2299.

19. Miles EA, Rees D, Banerjee T, Cazzola R, Lewis S, Wood R, Oates R, Tallant A, Cestaro B, Yaqoob P, Wahle KW, Calder PC: Age-related increases in circulating inflammatory markers in men are independent of BMI, blood pressure and blood lipid concentrations. Atherosclerosis 2008 , 196:298-305.

20. Giugliano RP, Braunwald E: The year in acute coronary syndrome. J Am Coll Cardiol 2014, 263:201-214.

21. Nash SD, Cruickshanks KJ, Klein R, Klein BE, Nieto FJ, Chappell R, Schubert $C R$, Tsai MY: Long-term variability of inflammatory markers and associated factors in a population-based cohort. J Am Geriatr Soc 2013, 61:1269-1276.

22. Zhu S, Patel KV, Bandinelli S, Ferrucci L, Guralnik JM: Predictors of interleukin-6 elevation in older adults. J Am Geriatr Soc 2009, 57:1672-1677.

23. Rodondi N, Marques-Vidal P, Butler J, Sutton-Tyrrell K, Cornuz J, Satterfield S, Harris T, Bauer DC, Ferrucci L, Vittinghoff E, Newman AB: Markers of atherosclerosis and inflammation for prediction of coronary heart disease in older adults. Am J Epidemiol 2010, 171:540-549.

24. Greque GV, Serrano CV Jr, Strunz CM, Soeiro A, Santos M, Pivateli F, Jacob JL, Pesaro AE, Nicolau J, Kalil-Filho R: Preprocedural statin therapy, inflammation and myocardial injury in low-risk stable coronary artery disease patients submitted to coronary stent implantation. Catheter Cardiovasc Interv 2013 Apr 16. [Epub ahead of print].

25. Korybalska K, Kawka E, Breborowicz A, Witowski J: Atorvastatin does not impair endothelial cell wound healing in an in vitro model of vascular injury. J Physiol Pharmacol 2012, 63:389-395

26. Sipahi I, Akay MH, Dagdelen S, Blitz A, Alhan C: Coronary artery bypass grafting vs percutaneous coronary intervention and long-term mortality and morbidity in multivessel disease: meta-analysis of randomized clinical trials of the arterial grafting and stenting era. JAMA Intern Med 2014, 174(2):223-230.

doi:10.1186/s12979-014-0023-7

Cite this article as: Kanikowska et al:: Age-related limitations of interleukin- 6 in predicting early mortality in acute ST-elevation myocardial infarction. Immunity \& Ageing 2014 11:23. 